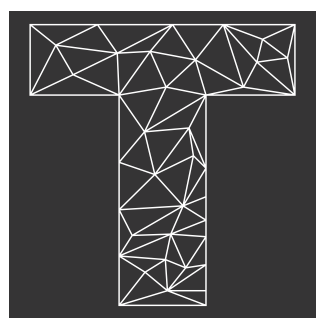

\title{
ASPECTOS A CONSIDERAR AL ABORDAR EL CAMBIO CLIMÁTICO DESDE EL ENFOQUE DE LA ECOLOGÍA POLÍTICA
}

Revista Trama

Volumen 9, número 1

Enero - Junio 2020

Páginas 20-51

ISSN: 1659-343X

https://revistas.tec.ac.cr/trama
Aspects To Consider When Dealing With Climate Change From A Political Ecology Perspective

María Laura Langhoff ${ }^{1}$

Fecha de recepción: 5 de febrero, 2020 Fecha de aprobación: 6 de mayo, 2020
Langhoff, M. L. (2020). Aspectos a considerar al abordar el cambio climático desde el enfoque de la ecología política. Trama, Revista de ciencias sociales y humanidades, Volumen 9, (1), Enero-Junio, págs. 20-51.

DOI: https://doi.org/10.18845/tramarcsh.v9i1.5268
1. Licenciada en Historia, doctoranda en geografía. Universidad Nacional del Sur. Bahía Blanca, Argentina. Código Postal 8000.

Correo electrónico: laura.langhoff@outlook.com

ORCID: https://orcid.org/0000-0002-1534-9534 


\section{Resumen}

El presente trabajo se propone abordar desde la perspectiva de la ecología política latinoamericana, una serie de aspectos del proceso de cambio climático. Estos son: el fomento del extractivismo en Latinoamérica y las movilizaciones de carácter socio ambiental que fueron surgiendo como consecuencia directa; las relaciones de poder que se evidencian entre las instituciones y países que motorizan la investigación y discusión a nivel global, desatendiendo alternativas para controlar efectos a nivel local; y, por último, el cambio climático como un discurso hegemónico que corre el riesgo de transformarse solo en eslogan, lo cual lleva a plantearse si no es adecuado hablar de crisis socio ambiental.

El marco teórico que brinda la ecología política latinoamericana se asienta en una profunda reflexión de la historia signada por la conquista. En su análisis son centrales las relaciones entre las elites políticas, económicas y culturales con las metrópolis y el despojo de recursos naturales.

La metodología utilizada se centró en la lectura y análisis de bibliografía tanto teórica como estudios de caso y notas periodísticas que se han producido en los últimos años en relación al tema.

La conclusión que se plantea destaca que el proceso de cambio climático se convierte en un eslogan que acaba conviviendo con actividades extractivas que contribuyen al agravamiento de dicho proceso, las cuales se continúan impulsando en Latinoamérica. Es necesario profundizar el pensamiento y prácticas decoloniales.

Palabras clave: ecología política; cambio climático; crisis socio ambiental; extractivismo.

\section{Abstract}

This paper focuses on a series of aspects, evident in dealing with climatic change, from the Latin American political ecology point of view. These are: the promotion of extractivism in Latin America and environmental and social movements that emerged as a direct consequence of this; the manifest power relations between institutions and countries that are leaders in research worldwide, which, at the same time, ignore alternatives to control pollution effects locally; and last, climate change as an hegemonic discourse which is at risk of becoming just a motto and makes us wonder if it could be suitable to talk about environmental crisis given this context.

The theoretical framework provided by Latin American political ecology sets its bases in a deep consideration of history marked by the conquest. In its analysis, relations between political, economic and cultural elites with metropolis and natural resources are key.

Methodology applied in the research focused on reading and analysis of theoretical bibliography as much as study cases and recent news stories on the subject.

We conclude that climate change process becomes a slogan that ends up co-existing with on-going extractive activities which contribute to the spoilage of environment itself. It is necessary to go further in decolonial reflection and practices.

Keywords: political ecology; climate change; socioenvironmental crisis; extractivism. 


\section{INTRODUCCIÓN}

La propuesta de este trabajo consiste en abordar desde el enfoque de la ecología política latinoamericana, aspectos que sobresalen en el análisis del cambio climático como proceso que impregna el interés político internacional desde fines del siglo XX. Estos aspectos son: el fomento del extractivismo en Latinoamérica y las movilizaciones de carácter socio ambiental que fueron surgiendo como consecuencia directa; las relaciones de poder que se evidencian entre las instituciones y países que motorizan la investigación y discusión a nivel global, desatendiendo alternativas para controlar efectos a nivel local; $y$, por último, el cambio climático como un discurso hegemónico que corre el riesgo de transformarse solo en eslogan, lo cual lleva a plantearse si es o no adecuado hablar de crisis socio ambiental.

El marco teórico eco-político crítico latinoamericano permite pensar al cambio climático desde otra posición, la latinoamericana signada por una historia de conquista y saqueo de sus bienes comunes. En tal sentido, es necesario plantearse que implica hablar de cambio climático desde los sectores de poder, ya sean gobiernos, instituciones o grandes empresas; y qué significa para los territorios afectados por procesos extractivistas históricos, los cuales se han acrecentado en las últimas décadas.

Este trabajo se asienta en la lectura y análisis de bibliografía y el cruce con casos actuales que se caracterizan por el fomento de actividades extractivas, como el caso argentino de Vaca Muerta y en Chile el conflicto en torno al agua con los actores que intervienen y su acumulación, junto con la relevancia que tienen los movimientos socio ambientales y sus luchas.

A continuación, el trabajo se organiza de la siguiente forma: se realiza un recorrido conciso sobre la ecología política latinoamericana y sus aportes a las discusiones socio ambientales, resaltando las contribuciones desde el pensamiento decolonial. En relación con ello se avanza sobre cómo se concibe el extractivismo y un breve repaso sobre su conceptualización. Asociado a la resistencia de las actividades extractivas, están los movimientos socio ambientales y su organización a través de asambleas. En base a lo expuesto hasta esta parte del texto, se 
plantea el interrogante sobre si cabe hablar de cambio climático o crisis socio ambiental. Por último, se exponen los aspectos para escrutar el cambio climático desde la perspectiva eco-política. 


\section{BREVE REPASO DE LOS APORTES DE LA ECOLOGÍA POLÍTICA}

Las preocupaciones en torno al deterioro medioambiental y su impacto en la sociedad, derivaron a finales de la segunda mitad del siglo XX en el estudio de las vinculaciones políticas y económicas en que se asienta dicho deterioro. La ecología política responde como una herramienta crítica y teórica a ese estudio. Se identifican una serie de tradiciones en el pensamiento eco-político, caracterizadas por trayectorias históricas, posiciones geopolíticas de las áreas donde se iniciaron, así como, por los problemas de investigación y preguntas a los que buscaron aportar. De este modo se distinguen tradiciones como la norteamericana, francesa, ibérica y la latinoamericana.

La tradición norteamericana se nutre de los aportes de la antropología y la geografía, algunos de sus referentes son Wolf (1972), Blaikie y Brookfield (1987) quienes desde la geografía en base a estudios rurales que efectuaron en África, entienden a la ecología política como el estudio para comprender las relaciones entre la sociedad y el medio ambiente, centrándose en los distintos niveles de acceso a los recursos. Otro referente es Robbins (2004) para quien, la ecología política implica estudios alternativos a la ecología apolítica, la cual se manifiesta a través de los conceptos de "ecoescasez" y la "modernización". A su vez, destaca la contribución que han tenido a este campo de conocimiento, diversas disciplinas como la sociología ambiental, los estudios sobre el desarrollo, la historia ambiental, entre otras.

Dentro de esta línea norteamericana, destacan los aportes de Tom Perreault (2015), cuyos trabajos de campo se han centrado en los conflictos en torno al agua en Latinoamérica, puntualmente Bolivia, lo que lo posiciona en un sitio crítico hacia cómo se desarrollaron los estudios eco-políticos en el hemisferio norte. Más allá de considerarla como un campo de investigación académico que tiene estrecha relación con el postcolonialismo, destaca que, como esfera de trabajo y acción social, debe tratar de cumplir tres compromisos: el teórico, ejercer un postpositivismo; el metodológico, desprenderse de los métodos positivistas y adoptar los métodos plurales que den voz a los sujetos; y el político, donde se enlaza la ética y la justicia social. Esta apertura que presenta Perreault, teniendo presente su formación en la academia norteamericana, se relaciona con el trabajo en Latinoamérica ${ }^{2}$.

2. Resulta interesante en este caso, leer su artículo en la Revista Estudios Atacameños, Arqueología y Antropología Sur Andina, número 51, (2015). 
La otra tradición es la francesa, donde sobresalen referentes como Gorz en la década de los sesenta y setenta con sus obras "Ecología y libertad" (1977) y "Ecología como política" (1979), sus contribuciones permitieron pensar la crisis de sobreacumulación que se estaba dando en relación a la crisis ecológica. Otro referente, Lipietz (2002) realizó abordajes de la ecología política y su sentido en el contexto del siglo XXI donde se atraviesa una degradación ambiental que exige nuevos planteos desde la sociedad y la política. Otra figura es Razmig Keucheyan (2016) quien desde la sociología indaga sobre los desafíos que supone la crisis ambiental actual a nivel global y las respuestas que brindan los organismos supranacionales y gobiernos poderosos. En este marco la ecología política adquiere sentido en la "hibridación de las luchas y la construcción de alianzas inéditas" (Keucheyan, 2016, p. 68).

En ambas tradiciones tiene un peso relevante la actividad académica, la ecología política supone la incorporación de nuevos objetos de estudio que van desde la tierra, el agua a los movimientos campesinos, indígenas y feministas. No obstante, a pesar de que su enfoque se sustenta en una postura marxista, responde a las necesidades de las realidades norteamericana y europea.

La línea de ecología política latinoamericana, desde la cual se propone realizar el abordaje, está atravesada por la historia y las realidades que se originaron desde la conquista. Por lo cual contiene un componente crítico que centra la atención en las relaciones de poder y las resistencias ante los embates del capital transnacional. En tal sentido es muy importante el pensamiento filosófico decolonial a partir del cual se desarrolla el pensamiento y acción crítica eco-política. Uno de los impulsores y referentes ineludibles en Latinoamérica es Alimonda (2017), según él la ecología política debe pensarse desde un lugar de enunciación, puesto que implica una construcción colectiva. Para ello propone pensar a la ecología política como "una elaboración político-intelectual de vanguardia que intenta con angustia responder a los tremendos desafíos que la época presenta para los pueblos de nuestro continente, reconociendo la necesidad ineludible de criticar los presupuestos civilizatorios de la modernidad y del desarrollo convencionales" (Alimonda, 2017, p.43). 
En relación con esto, la ecología política latinoamericana es un espacio en constante construcción, puesto que se nutre de distintas líneas de investigación que, de diversas formas involucran el feminismo, el campesinado, las reivindicaciones de los pueblos originarios, entre otras. Con base en estas consideraciones, su objeto de estudio son las relaciones de poder entre diversos sujetos en torno al acceso a los recursos naturales (Palacio, 2006).

En tanto, el economista catalán Joan Martínez Alier (2005) entiende la ecología política como una herramienta para comprender y estudiar los conflictos redistributivos, los que se definen como "los patrones sociales, espaciales y temporales de acceso a los beneficios obtenibles de los recursos naturales y a los servicios proporcionados por el ambiente como un sistema de soporte de la vida" (Alier, 2005, p. 105); además de considerar las formas en que los sectores sociales desplazados o las culturas marginadas, contribuyen con lo que se denominó "el ecologismo de los pobres". En este marco los lenguajes de valoración son espacios del saber que colaboran con otras formas de comprender la naturaleza.

Enrique Leff, resume en gran parte, qué conocimientos y sujetos adquieren protagonismo en el ejercicio de la ecología política, destacando su importancia como un campo de acción y compromiso.

En América Latina se alimenta de perspectivas provenientes de la filosofía, la epistemología, la ética, la economía, la sociología, el derecho, la antropología y la geografía, por autores y movimientos sociales que, más allá del propósito de ecologizar el pensamiento y la acción, están confluyendo en la arena política y en el estudio de las relaciones de poder que atraviesan al conocimiento, al saber, al ser y al hacer (Leff, 2006, p. 32 y 37).

El saber que se genera y circula en el entramado eco-político es clave en la construcción de nuevas alternativas de pensamiento y prácticas frente a los conflictos socio ambientales y las crisis que tienen este mismo origen.

En suma, este nuevo campo de conocimiento e investigación se propone incorporar las voces de los sujetos desplazados y silenciados 
en el proceso histórico de conquista, ocupación y explotación de los territorios. Para ello busca incentivar el diálogo de saberes donde deben tener participación los pueblos originarios, los campesinos, las mujeres, los afrodescendientes y los nuevos grupos excluidos como el caso de los desplazados ambientales.

En el caso de Sud América el aporte desde la ecología política se ancla en la crítica y la de-construcción de la colonialidad sobre la que se asentó y, aún permanece, la matriz de dominación y extracción de recursos ${ }^{3}$. Ello supone el desarrollo de un pensamiento decolonial que se complementa con una indagación natural-colonial (Alimonda, 2011). En este proceso de releer y analizar desde otros ángulos los procesos históricos de ocupación de los territorios, la naturaleza pasó a ocupar una posición cada vez de mayor importancia.

En tal sentido, hoy puede afirmarse que el pensamiento crítico social latinoamericano y caribeño permite comprender la raíz de los conflictos ambientales y los nuevos sujetos que se encuentran afectados y se organizan por medio de asambleas y organizaciones que les permiten visibilizar su realidad. Los conflictos socio ambientales son el resultado de renovadas formas de expropiación de los bienes comunes, los territorios y las fuentes que deben asegurar la vida, en beneficio del sistema global capitalista.

En este contexto y desde la perspectiva eco-política, se analizan representaciones y conceptos que a través del tiempo y bajo diversos procesos, adquieren nuevas significaciones. Tal es el caso de aquello que entendemos por "naturaleza", ¿está bien hablar de"recursos naturales" en el marco extractivista o es urgente hablar de "bienes comunes?; ¿cuáles son los aspectos éticos que involucra la actual etapa de expoliación de tierras, agua y biodiversidad?; ¿cómo repercute la misma sobre la política y economía de los países sudamericanos?; ¿qué nuevas lógicas se articulan para la obtención de recursos?; ¿qué papel juega el sistema político tradicional?; ¿qué sucede con el sistema democrático?; ¿qué actores mundiales se benefician y cuales se perjudican? Estos son algunos de los interrogantes que se formulan desde el posicionamiento eco político.

3. Es así cómo se articuló el Programa de Investigación Modernidad/Colonialidad, de investigación integrado por referentes sudamericanos (Alimonda, Escobar, entre otros) y norteamericanos interesados en analizar y deconstruir la matriz de pensamiento impuesta. Este grupo de trabajo se "organiza a partir de una crítica de base histórico-cultural y epistemológica de la modernidad, cuestionando las grandes narrativas interpretativas de la misma, a lo largo de cinco siglos" (Alimonda, 2011, p.23). 
En esta línea es que se plantea un cuestionamiento profundo sobre la matriz histórico-cultural que se ha impuesto y arraigado en nuestra América Latina y el Caribe (Esquema 1).

Esquema 1. Aportes de la ecología política.

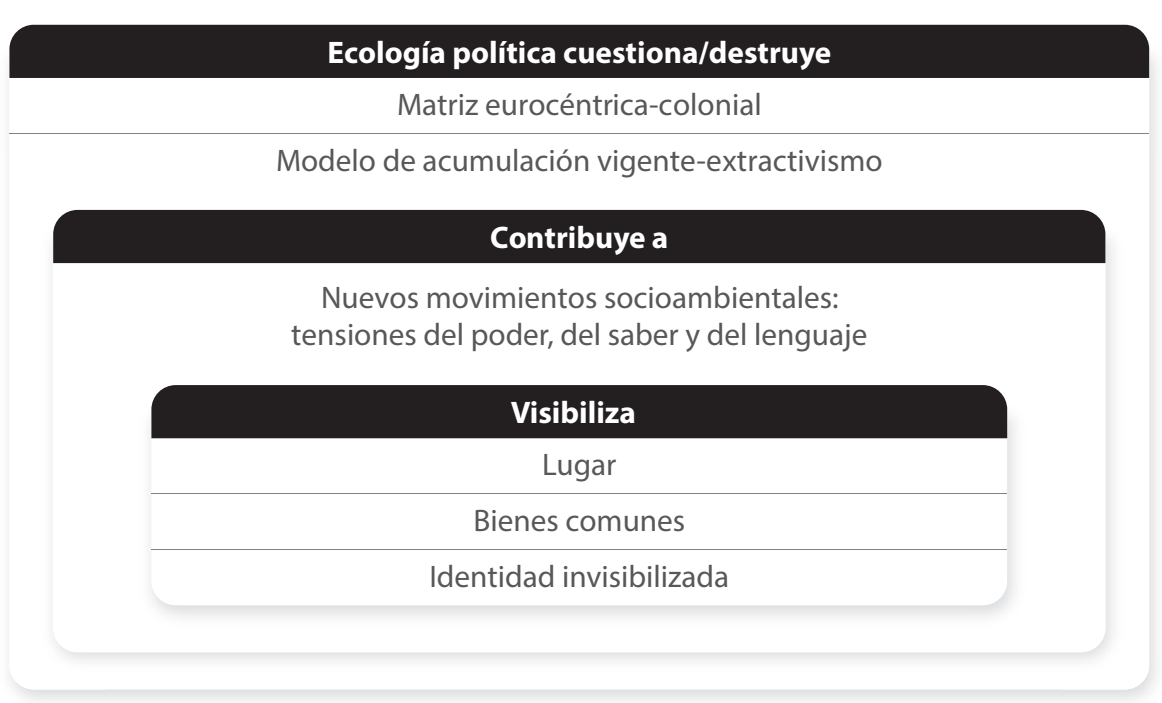

Fuente: Elaboración propia.

La deconstrucción de la matriz eurocéntrica y colonial, se centra en estudiar cómo se han construido los grandes relatos desde las metrópolis y, cómo éstos han operado sobre la política, economía y sociedades locales. Este es un proceso que se fue construyendo, imponiendo y reformulando a lo largo de los siglos bajo dominación ibérica y, luego, anglosajona (Dussel, 2000). 


\section{LA MATRIZ EXTRACTIVISTA}

Tanto Centro América como Sudamérica mantuvieron buena parte de su base económica; históricamente desde la colonización europea hasta la actualidad, son exportadoras de materias primas. Estos recursos naturales han variado a lo largo del tiempo de acuerdo con las necesidades de las metrópolis y, en épocas más recientes, de la economía mundial dirigida por multinacionales e intereses financieros.

Actualmente uno de los ejes en torno al cual se debate y trabaja en la ecología política es el extractivismo. Desde la década de los noventa se están desarrollando actividades de carácter extractivo a gran escala; éstas implementan tecnología perjudicial tanto para el medio ambiente como para las personas. El avance de estas prácticas se produce en un contexto donde se incorporan nuevos territorios para la extracción de materias primas, en muchos casos, estratégicas. Tal es el caso de la megaminería (del cobre, oro, coltán, litio, entre otros), la fractura hidráulica (para obtener gas y petróleo a los cuales ya no puede accederse por los métodos convencionales), la "sojización" de la pampa húmeda y la extensión de la frontera agrícola a tierras, hasta ahora, consideradas marginales. El proceso extractivista contemporáneo se genera en el marco de lo que Harvey denomina "acumulación por desposesión" (Harvey, 2004), la cual avanza directamente sobre el medio ambiente y la vida de los pueblos. Estas son, también, las formas de desarrollo extractivista que se producen en toda América. Si bien Harvey advierte que este avance sobre nuevos espacios se dio desde la década de los setenta, con el neoliberalismo en Estados Unidos y Gran Bretaña, en América Latina adquirió impulso en los noventa y se mantiene hasta la actualidad. El avance de los gobiernos progresistas en la región no alteró este proceso, sino más bien facilitó la incorporación de nuevos capitales como los de origen chino ${ }^{4}$.

Uno de los planteos eco-políticos lo realiza el investigador uruguayo Eduardo Gudynas, quien señala cómo influyeron los gobiernos progresistas en la continuidad y expansión del extractivismo. Para este autor, el extractivismo consiste en la explotación de grandes volúmenes de recursos naturales que no se procesan y son trasladados por diversos medios hasta puertos o terminales para su exportación.

4. La presencia de los capitales chinos se encuentra en tanto en actividades mineras, de monocultivos, como en la construcción de mega obras. Un ejemplo es la construcción del canal de Nicaragua que despertó una masiva oposición de la población que se veía afectada. 
Por otro lado, Gudynas también entiende que se está frente a un neoextractivismo ${ }^{5}$. Este concepto se volvió parte de los debates actuales debido a las acciones de los gobiernos progresistas que han reforzado una reprimarización de la economía. En este sentido afirma:

Los gobiernos progresistas o de la nueva izquierda implantaron cambios en distintos sectores extractivos donde posiblemente los más conocidos son las reformas del manejo petrolero en Bolivia, Ecuador y Venezuela. Muchas organizaciones ciudadanas tenían esperanza que esos y otros cambios serían los primeros pasos para reformas más profundas. Pero eso no ha ocurrido y, por el contrario, han proliferado los emprendimientos extractivos con impactos cada vez más serios, sin avances en controles ambientales o consultas ciudadanas. (Gudynas, 2013, p.8).

Se puedeagregar que el neoextractivismo involucra tecnologías que producen un alto impacto en el medio, con efectos que son permanentes.

Junto al proceso extractivista, Gudynas distingue otro que es coincidente con la violencia que supone la acumulación por desposesión: la extrahección. Consiste en la apropiación con violencia de los recursos naturales franqueando los marcos del derecho. Ello sucede cuando pueblos originarios son cercados, desplazados de sus territorios para ocuparlos bajo nuevos usos, por ejemplo, expansión de monocultivos, o en los casos en que el capital y el Estado se apropian del agua de un río para la construcción de una represa, perjudicando a quienes viven aguas abajo ${ }^{6}$.

Por su parte, Machado Araoz contribuye a la comprensión del extractivismo, sobre todo minero, a través de la incorporación en esta práctica, de los que denomina como "dispositivos expropiatorios"; estos abarcan las reformas neoliberales impulsadas en las últimas décadas, los actores, prácticas y estrategias que intervienen, sumándose todo el andamiaje simbólico discursivo interviniente en la legitimización extractivista (Machado Araoz, 2010, p. 1).

5. Galafassi (2017) plantea una crítica interesante a esta diferenciación que se hace entre extractivismo y neoextractivismo, además de cuestionar el uso abundante que se realiza de este término en los estudios socio-ambientales, dado que desde su postura siempre se han dado ciclos extractivos, más en el caso americano. 
En el entramado extractivista es necesario considerar la relevancia que adquieren los lugares, entendidos como el espacio que se resignifica para quienes viven allí, ante el avance de proyectos que conducen al despojo de sus bienes comunes y amenazan su subsistencia. Arturo Escobar es uno de los investigadores ha problematizado el lugar en este contexto, tomando como ejemplo el caso de las comunidades negras en el Pacífico colombiano. No necesariamente hay que descartar lo global, sino recuperar la importancia del lugar y su interacción con la cultura y los cuerpos. Al decir de Escobar "reconocer que el lugar, el cuerpo y el ambiente se integran unos con otros; que los lugares recogen cosas, pensamientos y memorias en con-figuraciones particulares; y que el lugar, un evento más que una cosa, es caracterizado por su apertura y no por una identidad unitaria" (Escobar, 2010, p. 135).

Si bien la literatura que aborda el extractivismo es amplia, hay investigadores que discuten la supuesta novedad extractivista. Al respecto Galafassi y Riffo (2018) consideran que "el extractivismo es solo un instrumento para la acumulación capitalista. Por lo tanto, debe ser tratado conceptualmente como tal. El eje está en la lógica de acumulación y el extractivismo es solo una herramienta para el inicio de este proceso" (Galafassi y Riffo, 2018, p. 116). Desde su crítica no existe algo como un neoextractivismo, sino que el extractivismo está presente desde la etapa de la conquista.

6. Un ejemplo es el conflicto por el río Atuel entre las provincias de Mendoza y La Pampa, en Argentina (Langhoff, et al. 2017). 


\section{LOS MOVIMIENTOS SOCIO AMBIENTALES}

En función de lo abordado en el apartado anterior y lo expuesto en el esquema $\mathrm{N}^{\circ} 1$, se puede observar cómo desde la ecología política contribuye en la visibilización de los conflictos que se producen en este marco de explotación del medio ambiente y la población afectada. Las poblaciones involucradas no son actores pasivos, la experiencia extractivista condujo a la conformación de movimientos sociales que se articulan en asambleas para resistir los embates del capital con apoyo del Estado. Estas nuevas manifestaciones ahora centran su eje de acción y reclamo en la defensa de los bienes comunes para el sostenimiento de la vida?. Algunos investigadores denominan a estos como "nuevos movimientos sociales", ya que "han descentrado las demandas desde la contradicción básica capital-trabajo a la contradicción capitalcondiciones de producción, han puesto sobre el tapete muchos mecanismos de alienación cultural y también la problemática de los bienes comunes más allá de la cuestión de clase" (Galafassi, 2014, p. 85).

En Argentina, a comienzos del siglo XXI, se fue conformando una red de asambleas socio ambientales, la Unión de Asambleas Ciudadanas, cuyas luchas están centradas en la defensa de los territorios, bienes comunes (agua, suelo, aire) y la salud. Además, en las últimas décadas se han producido (y continúan produciéndose) conflictos en los que la población afectada actúa y participa con mayor información. Dentro de las asambleas se fueron tejiendo una red de saberes a partir de la experiencia, que sirven luego como alertas para el resto de la población. Ante el avance en nuevos espacios de empresas que buscan extraer/explotar recursos naturales, las comunidades locales buscan informarse y contactarse con otras poblaciones que ya vienen sufriendo estas experiencias.

Una particularidad que se da en estos movimientos sociales es la intervención de profesionales de diversas disciplinas, que contribuyen a la lucha desde sus conocimientos. Se convierten en investigadores militantes y enriquecen el diálogo de saberes, tanto al interior de los movimientos como hacia el exterior.

Las asambleas socio ambientales son un actor clave para comprender cómo afectan los impactos del extractivismo al conjunto de la sociedad, como así también, de presión política. Las mismas son

7. Para el caso de Argentina uno de los movimientos sociales ligado al territorio y medioambiente, fue el "No a la mina" que se formó en Esquel en 2003 y frenó la instalación de una mina para la extracción de oro 
auténticos espacios de intercambio de saberes y experiencias, donde, además, se incorpora el conocimiento científico comprometido con las comunidades y no con el capital privado. Si bien desde el Estado y el sector privado (mineras, petroleras, compañías agroquímicas), son invisibilizados, amenazados y criminalizados, su voz pone en evidencia la crisis socio ambiental que se está produciendo.

Desde la perspectiva de las asambleas socio ambientales adquiere un nuevo significado el territorio y los recursos que se defienden. En este sentido el lenguaje se convierte en un instrumento donde se ven plasmadas las diferencias entre las transnacionales y los Estados y las asambleas. Para los primeros solo se trata de recursos naturales estratégicos con valor de cambio, commodificables; en tanto para las resistencias desde los territorios, se trata de bienes comunes necesarios para el desarrollo de la vida y, en los que en muchos casos, se asienta la identidad ${ }^{8}$. En relación con esto y retomando el concepto de acumulación por desposesión, Seoane plantea cómo se da la lucha por los bienes comunes:

Este proceso de acumulación por desposesión supone entonces un feroz proceso de mercantilización. Feroz porque la mercantilización supone despojo; o para decirlo con otras palabras arrebatar estos bienes que eran de uso común o formaban parte del hábitat de vida o, incluso, eran explotados bajo otras formas vinculadas a la reproducción local. Este proceso de despojo es lo que los movimientos sociales han bautizado como "saqueo" (Seoane, 2011, p. 83).

Es así como desde el movimiento socio ambiental se genera una nueva herramienta de análisis a través del lenguaje, para inquirir desde los territorios afectados, a las lógicas de extractivistas que continúan operando.

8. Como el caso de la asamblea No a La Mina surgida en Esquel, Argentina, en 2003 en oposición a la explotación de una mina de oro. Si se llevaba adelante ese emprendimiento, se perdía también la calidad de vida de la zona. 


\section{V. ¿CAMBIO CLIMÁTICO O CRISIS SOCIO AMBIENTAL?}

En relación al marco teórico planteado y el auge de las investigaciones sobre el extractivismo, en los últimos años se suma la emergencia y urgencia del cambio climático. Si bien el clima planetario atravesó diversos ciclos, es en los últimos doscientos años cuando se comenzaron a generar alteraciones como la acumulación de gases en la atmósfera, por el aumento de la industrialización - es decir-con el desarrollo del sistema capitalista basado en una explotación desaprensiva de la naturaleza y de forma progresiva en diversos lugares del mundo. La consecuencia es el registro de un aumento del $70 \%$ de emisiones gaseosas de efecto invernadero (Bertinat y Ochandio, 2018). Estos gases son el dióxido de carbono, metano, óxido nitroso y los halocarbonos.

Las inquietudes entorno al calentamiento global, comenzaron en las últimas décadas del siglo XX. En 1988 por iniciativa de la ONU, a través de organismos como el Programa de las Naciones Unidas para el Medio Ambiente (PNUMA) y la Organización Meteorológica Mundial, se creó el Panel Intergubernamental de Expertos Sobre el Cambio Climático (IPPC en su sigla en inglés). Este organismo tiene la función de ofrecer una visión clara y científica sobre los conocimientos actuales en relación al cambio climático y las repercusiones a nivel ambiental y socioeconómico.

No obstante, estas acciones no deben desligarse de las primeras convenciones e informes efectuados en la década anterior, los cuales derivaron en la búsqueda del objetivo del desarrollo sostenible. Desde entonces se realizaron reuniones cumbres, algunas relevantes como la de Río $92^{9}$ y Kioto 97, donde se elaboró el Protocolo homónimo, cuyo objetivo es reducir las emanaciones de gases de efecto invernadero, estableciendo plazos. Entró en vigencia en el año 2005 y adhirieron 187 países.

Estos compromisos no fueron suficientes para evitar el agravamiento del calentamiento global y sus consecuencias. A inicios del siglo XXI ya se pudieron ver los efectos cada vez más devastadores de fenómenos climáticos como huracanes, tornados en áreas no habituales, sequías extensas agravadas con alto riesgo de incendios, olas de calor intensas, precipitaciones violentas y riesgo de pérdida de territorios insulares ante el aumento del nivel del mar10. Estos son solo algunos de los efectos que ya comienzan a vivirse.

9. Para profundizar se recomienda el trabajo de Estenssoro Saavedra (2014).

10. En este caso es necesario considerar la situación que enfrentan naciones insulares del Pacífico como Kiribati, Tuvalu y en el Índico en el caso de las Maldivas. 
Debido a estas evidencias, hay una presión internacional en parte por los organismos supranacionales ya mencionados; como así también por la movilización de amplios sectores de la sociedad afectados, muchos de los cuales, como se vio en el apartado previo, se vienen manifestando desde fines de siglo XX en el caso de Latinoamérica, a los que se suman ahora movilizaciones de jóvenes, sobre todo, en el hemisferio norte" los cuales impulsan a poner en agenda el tema. Es así como el cambio climático se fue incorporando en los discursos gubernamentales y de diversas instituciones. Esta eclosión de la crisis climática como problemática a nivel global, se convirtió un tema de agenda.

En este punto es donde desde un enfoque eco-político se debe interpelar a quienes hablan del cambio climático desde posiciones estratégicas asociadas al poder, como por ejemplo los denominados "líderes mundiales", organismos supranacionales e instituciones científicas. Así surgen preguntas como ¿Quiénes hablan de cambio climático? ¿Qué desigualdades se ocultan detrás de este proceso? ¿Se debe hablar de cambio climático o crisis socio ambiental? La necesidad de interpelar no busca desviar la atención sobre lo que este proceso significa, sino ver quienes hablan, si son Estados, organismos o el campo científico. ¿Son atribuibles todas las problemáticas ambientales al cambio climático o este es un elemento que se suma, en muchos casos, a procesos de deterioro socio ambiental de larga data?

En esta línea al hablar de socio ambiental se pone el acento en el hecho de que el deterioro y los conflictos que se producen no pueden ser considerados exclusivamente como sociales o ambientales. La sociedad y el medio en que se desarrolla, no están separadas, "No hay dos crisis separadas, una ambiental y otra social, sino una sola y compleja crisis socio-ambiental" (Francisco, 2018, p.86).

Los procesos que afectan al ambiente y la sociedad son innumerables, en muchos casos estos tienen una historia, donde intervienen diversos aspectos como decisiones políticas y rentabilidad económica. Un ejemplo de ello puede ser la construcción de una represa para generación de energía y almacenamiento de agua para riego. En esos casos se supone que el cambio climático es una variante que influye,

11. Una referente es Greta Thunberg y el movimiento Friday for Future que fue expandiéndose al resto del mundo, convocando algunas de las movilizaciones más numerosas en torno al cambio climático en los últimos tiempos. 
pero no de la misma forma en cada lugar. Lo que amerita pensar distintas estrategias para evitar sus efectos considerando las particularidades inherentes.

Considerando esto, se debe hablar de crisis socio ambiental. El concepto es más complejo porque engloba los diferentes procesos históricos que se conjugan dentro de la matriz capitalista, desde lo económico, cultural y político, que impactaron en diferentes lugares y regiones, cuyas consecuencias hoy son evidentes. Además, hace necesaria la inclusión de los diferentes actores y ser crítico con el sistema de producción imperante. Desde este enfoque, se buscan e identifican las raíces de la crisis y de las desigualdades (esquema 2). Como parte de ese proceso de indagación, se vuelve a cuestionar, en el caso del hemisferio sur, la mentalidad colonialista, el occidentalismo y el eurocentrismo de los sectores de poder y los gobiernos, que buscan continuar con las políticas extractivistas. Como resultado de la crítica de la crisis socio ambiental se intentan generar alternativas al sistema productivo depredatorio ${ }^{\mathbf{1 2}}$.

Hablar de cambio climático para los Estados es hablar de un compromiso con el cual éstos deben cumplir y se resume casi en parámetros cuantificables ${ }^{13}$. No obstante, en la realidad de sus territorios se producen las contradicciones. Se continúan implementando e impulsando proyectos extractivistas que responden a necesidades del mercado y no a las de las comunidades. Hablamos de proyectos extractivistas como Vaca Muerta en Argentina, o algunos de los proyectos megamineros localizados en la zona cordillerana. Estos agravan situaciones previas (despojo de tierras, despoblamiento, intensificación de disputas por recursos como agua, tierra, bosques, etc.) y no contribuyen a mitigar los efectos del cambio climático, sino que generan nuevas complicaciones, como mayores emanaciones de gases como el metano (caso del fracking) o la destrucción de glaciares. En suma, no se comprende la complejidad que subyace a la crisis socio ambiental que atravesamos. El cambio climático funciona como un parche que permite asumir solo una parte de las consecuencias.

12. Un ejemplo son las alternativas que adquirieron voz en las últimas dos décadas como el Buen Vivir y el Sumak Kawsay, que fueron incluidas en las constituciones de Bolivia y Ecuador. O la posibilidad de desarrollo de energías renovables.

13. Como las estadísticas de emisiones de GEl (gases de efecto invernadero) y concentración global de GO2. 


\section{Esquema 2. Aristas de la crisis socioambiental.}

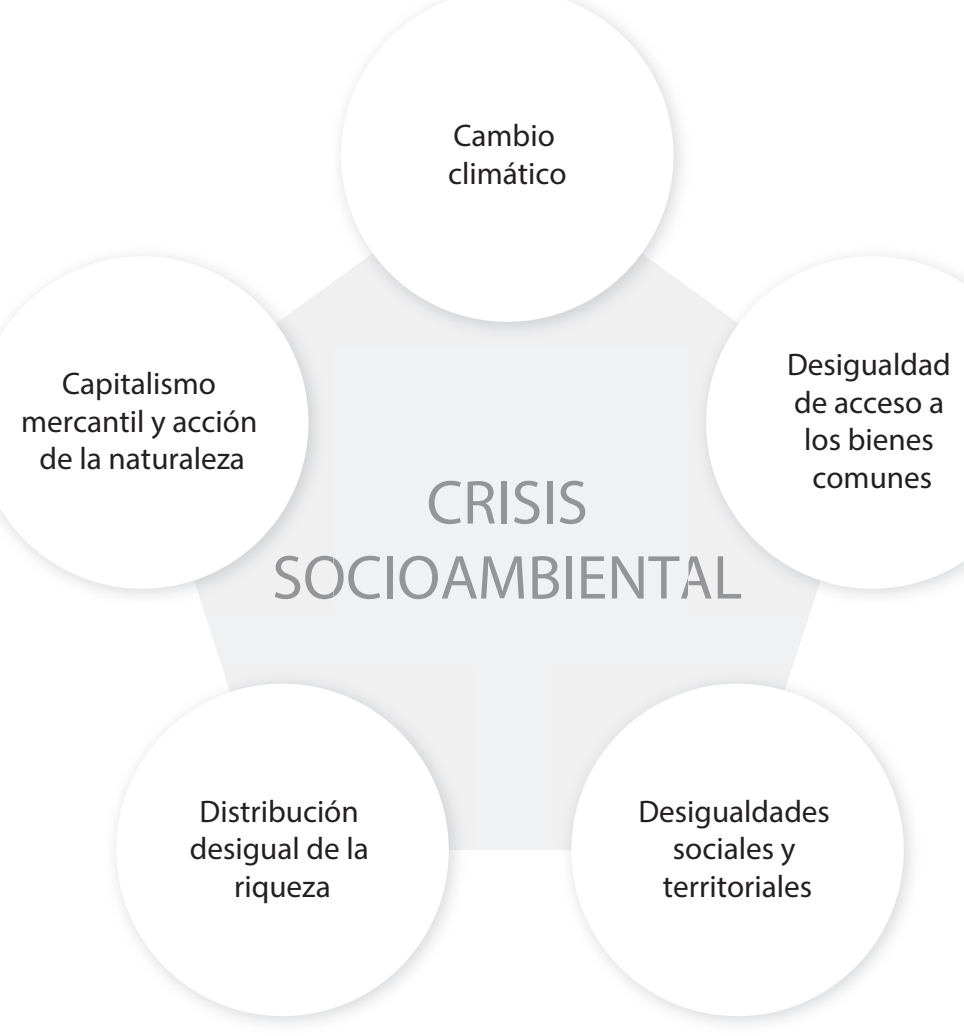

Fuente: Elaboración propia. 


\section{ASPECTOS PARA PROFUNDIZAR}

En este contexto y desde un enfoque ecopolítico, surgen algunos aspectos a tener en cuenta, el desarrollo de actividades extractivas en Latinoamérica así como el riesgo de invisibilizar conflictos socio ambientales de larga data que ponen en evidencia el deterioro del ambiente; relacionado con esto, las manifestaciones y movilizaciones de carácter asambleario que vienen advirtiendo de los impactos de actividades extractivas en los territorios y comunidades; en el cambio climático también se exponen relaciones de poder, que se evidencian entre qué organismos investigan y planifican y quiénes deben aplicarlos, desatendiendo las alternativas para morigerar y atender los efectos a niveles locales; y, por último, utilizar el cambio climático como un discurso de buenas intenciones (sobre todo por parte de los gobiernos y el sector privado) pero sin aplicar políticas y prácticas concretas que al respecto transformen las estructuras de poder, de producción y subjetivas.

En relación al primer aspecto, distintos proyectos extractivistas se vienen impulsando en diversos territorios, tanto del sur como el norte global (Ochandio, 2018), han ocasionado alteraciones irreversibles, en muchos casos, a nivel ecosistemico y socioeconómico. Un ejemplo característico es la megaminería y los mecanismos económicos y políticos que la legitiman, con el uso intensivo de agua, químicos y la desarticulación social de las comunidades que sufren tanto los impactos de la actividad en forma directa (por ejemplo, la contaminación y destrucción de fuentes de agua dulce como ríos, lagos y glaciares), como a través de sus pasivos ambientales. Estos procesos extractivos están presentes desde fines del siglo $X X^{\mathbf{1 4}}$. Su ejecución comenzó a comprometer las disponibilidades de agua, acrecentando las disputas; como así también su desarrollo se puede asociar a la concreción de otras obras como las represas para producción de energía y almacenamiento de agua.

Otro tanto sucede con el fracking ${ }^{15}$. Este método para extraer gas y petróleo por fractura hidráulica, se fomenta en algunos países con reservas petroleras y se prohíbe en otros donde se consideraron los efectos negativos que acarrea, tanto sobre los acuíferos, la sismicidad y el impacto en las poblaciones donde se lleva adelante. En Argentina, la formación no convencional de Vaca Muerta (imagen 1), cuya potencialidad fue descubierta en 2011, es donde se aplica este método para la extracción.

14. En el caso de Argentina y Chile fue fundamental el Tratado sobre Integración y Complementación Minera que se firmó entre ambos países en 1997, el cual cubre una extensión de 5000 kilómetros compartidos de cordillera donde se encuentran diversos minerales extraíbles. El Tratado fue reafirmado en el año 2017, por ambos países. 
Imagen 1: Ubicación de la formación Vaca Muerta en Argentina.

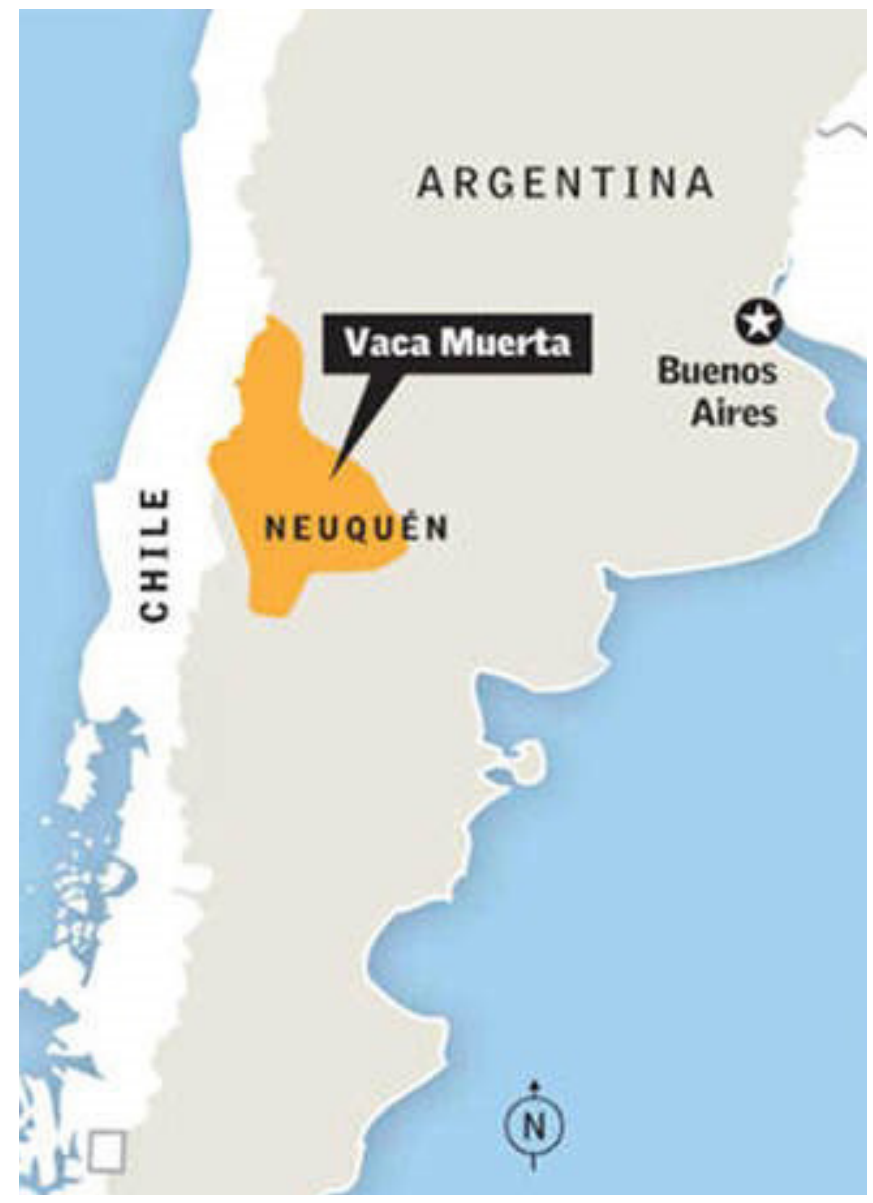

Fuente: Pappalardo, 2018.

La actividad del fracking está respaldada por los gobiernos tanto nacional como provincial. Si bien el shale gas que se obtiene por este método se afirma que marca la transición hacia energías renovables y la soberanía energética logrando el autoabastecimiento, los efectos que tiene sobre el clima, específicamente, no son alentadores. Según el IPCC $^{\mathbf{1 6}}$, en el año 2013, "el metano es aún peor para el clima de lo que se pensaba previamente. El IPCC determinó que el metano es un gas de efecto invernadero 34 veces más potente que el $\mathrm{CO} 2$ en un intervalo de

15. Por medio de esta técnica se extrae gas y petróleo contenido entre las rocas durante millones de años a grandes profundidades, para ello deben inyectarse enormes cantidades de agua y químicos para liberar los hidrocarburos. 16. Intergovernmental Panel on Climate Change. 
100 años y, 86 veces más potente en un plazo de 20 años" (Concerned Health Professionals of New York \& Physicians for Social Responsibility; 2015, p. 128).

En el caso de Argentina, una posición ambientalista de los dos últimos mandatarios en relación al cambio climático y el desarrollo de proyectos como el de Vaca Muerta, es favorable, mientras que por otro lado manifiestan, al menos en la discursividad, una posición de ambientalista, contradictoria con los hechos. En el discurso de asunción como presidente de la Argentina por parte de Alberto Fernández está presente el compromiso con el medio ambiente:

La Argentina necesita una política ambiental activa que promueva una transición hacia un modelo de desarrollo sostenible, de consumo responsable y de valoración de los bienes naturales. En esa búsqueda, estamos inspirados en la Encíclica Laudato Si de nuestro querido Papa Francisco, carta magna ética y ecológica a nivel universal (...) Reafirmamos nuestro compromiso con el Acuerdo de París. Promoviendo el desarrollo integral y sostenible mediante una transición justa que asegure que nadie quede atrás. Estas medidas son esenciales para entender la vulnerabilidad del país. Y en particular de los sectores más desprotegidos que son los que más sufren los efectos del cambio climático (Fernández, 2019, p. 9).

Si bien la consideración del medio ambiente en su discurso es alentadora, este entusiasmo se diluye con los incentivos a Vaca Muerta y la megaminería:

"Vaca Muerta" para nosotros es algo primordial, si sabemos que allí hay fuentes de recursos para el futuro y hablamos también de minería y claro que también la minería es un tema primordial (...) Y en Mendoza que salga una ley para que Mendoza, también, se involucre en la explotación minera (Fernández, 2019, s/p.).

Este posicionamiento es la continuación de las políticas anteriores en el tema medio ambiental, aunque ahora se incorpora un discurso de justicia social, las contradicciones son muy fuertes. 
Paralelamente, se deben tener presentes la imposición de políticas neoliberales que, en el caso de Sudamérica, abrieron las fronteras de los países a la expoliación de sus bienes comunes. Fueron cómplices de este modelo las dictaduras que interrumpieron la institucionalidad política de la mayoría de los países sudamericanos. Un caso particular es Chile (esquema 3), en cuya Constitución del 1980 y el Código de Aguas sancionado un año después, entregó el agua al mercado. Como consecuencia, en la actualidad "Chile es un país con la mayoría de sus 101 cuencas hidrográficas en crisis, el $72 \%$ de su territorio en riesgo de desertificación y sus derechos de agua sobreotorgados" (Wehr y Roose, 2017, p. 23).

Esquema 3: Simplificación del trasfondo de la crisis hídrica en Chile.

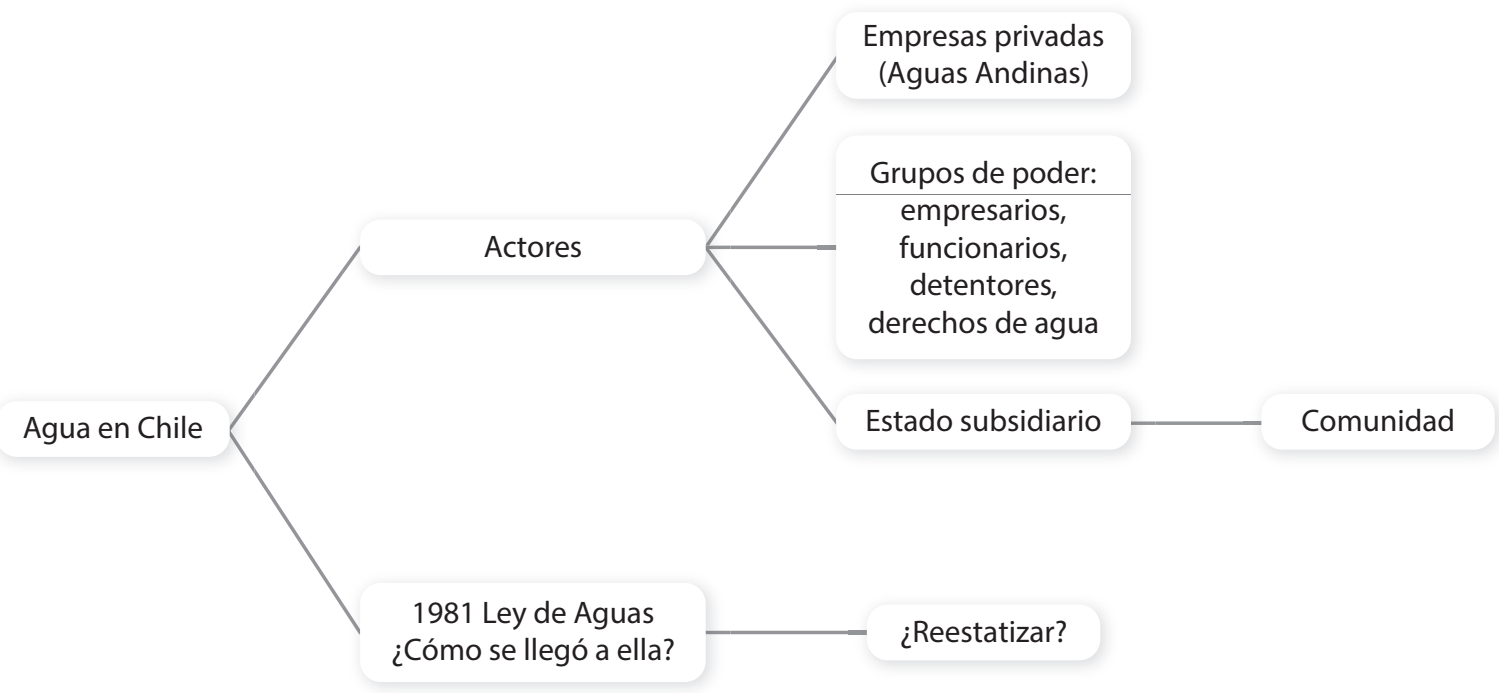

Fuente: Elaboración propia.

Estos procesos extractivo-contaminantes-desestructurantes de los territorios, han generado conflictos socio ambientales que, si bien son locales y en algunos casos regionales, pues se pueden ver afectados más de un país, se encadenan con otros acaecidos en otros lugares. En este sentido adquieren relevancia las movilizaciones y organización de los reclamos por medio de asambleas y movimientos socio ambientales. 
En 2019 las manifestaciones mundiales para crear conciencia sobre las consecuencias del cambio climático, provocaron que desde medios hegemónicos e, incluso, sectores gubernamentales, se coloque el tema medio ambiental en agenda ${ }^{\mathbf{1 7}}$. Pero las acciones de asambleas socio ambientales en lucha por el ambiente ya encendieron la voz de alarma mucho antes.

En relación a las redes de poder en las que se inserta el concepto de cambio climático, es necesario atender a las propuestas que desde allí se proponen para morigerar los efectos. En este sentido Keucheyan (2016) Ilama la atención sobre cómo Estados Unidos entiende el cambio climático y su impacto en la geopolítica, es percibido como un riesgo trasnacional al igual que el terrorismo. Esta apreciación es compartida también por la OTAN ya que "en el futuro la OTAN podría desempeñar un papel clave en la gestión de los efectos del cambio climático sobre la 'seguridad colectiva'"' (Keucheyan, 2016, p. 126).

El riesgo está en caer en un discurso hegemónico que deje en segundo plano a otras alternativas que pueden contribuir a la resolución de situaciones de crisis socio ecológica que están atravesadas por las particularidades de cada lugar. Por ejemplo, retomando el caso del agua en Chile, la escasez y conflictos en torno a su acceso, tienen larga data, agravándose por las distorsiones climáticas. En este sentido, sería reduccionista atribuir la escasez hídrica solo al cambio climático. Lo mismo sucede en el caso de las ciudades que se convierten en islas de calor ${ }^{18}$, en este caso hay causas como la falta de planificación urbana, que generan una situación que se agrava con el proceso de calentamiento global.

Por último, el cambio climático, en tanto concepto es incorporado en los discursos de gobiernos, instituciones y empresas. En este último caso, se incluye este lenguaje de valoración ecoeficientista (Martínez Alier, 2005) en el marco de la responsabilidad social empresaria. Aquí es posible afirmar que se tiende a crear una homogenización, al volver intentar abarcar una totalidad, desconociendo las particularidades de los lugares y las regiones. Es decir, sus itinerarios históricos, cómo están mediadas culturalmente las relaciones con el entorno natural y las estrategias que surgen de ello para enfrentar consecuencias originadas en el desequilibrio ambiental.

17. Para el caso argentino fue coincidente la relevancia que adquirió el cambio climático como tópico, con la campaña para elecciones presidenciales, puesto que la mayoría de los candidatos lo incluyó en discursos y debates. 
De esta forma, el concepto acaba por convertirse en un eslogan como sucede con el discurso de la sostenibilidad (Swyngedouw, 2011). Se crea un ámbito donde ese eslogan se adapta y se continúa interviniendo en los territorios de forma voraz, como sucede en Argentina con la fractura hidráulica para extraer gas y petróleo, cuando está comprobado que esta actividad es una de las que libera cantidades importantes de gas metano a la atmósfera (Bertinat y Ochandio, 2018).

18. Este es un efecto que se produce en las ciudades donde la densificación edilicia y el uso de materiales como el asfalto, generan una retención del calor lo cual produce un aumento significativo de las temperaturas urbanas en relación al entorno rural. 


\section{REFLEXIONES FINALES}

Es evidente que en las últimas décadas se está produciendo un deterioro del medio ambiente a escala planetaria, el cual afecta directamente a la sociedad de diferentes formas, siendo la situación en algunos países sensiblemente grave. Estas transformaciones que son producto del sistema de producción capitalista, comenzaron a advertirse en la segunda mitad del siglo XX. Gran parte de estas transformaciones son consecuencia del cambio climático.

Este concepto que da cuenta de un proceso histórico de intervención humana intensa en el medio ambiente, amerita ser analizado profundamente desde el enfoque ecopolítico tomando la tradición de pensamiento de la ecología política latinoamericana y caribeña, sin obviar los procesos extractivistas de los que es objeto Latinoamérica. Para esto es necesario incorporar la experiencia de las movilizaciones populares entorno a las condiciones sociales y ambientales, que cuentan con décadas de historia. La realidad de los países latinoamericanos está atravesada por innumerables conflictos socio ambientales, localizados territorialmente, con comunidades afectadas. A diferencia del cambio climático, que es presentado como un problema a nivel global en el que aparentan tomar decisiones solo algunos sectores con poder a nivel internacional.

El discurso del cambio climático esgrimido por gobiernos, instituciones diversas y el sector empresarial, se reproduce prolíficamente en medios, discursos políticos y demás espacios. Tanto que se convierte en un eslogan al no proponerse cambios sustanciales en el sistema de producción, distribución o transferencia de riquezas, capitales y consumo, es decir, continuar, por ejemplo, manteniendo la matriz energética basada en el petróleo. Este acaba siendo un tópico que entra en contradicción con la práctica, pues se continúan promoviendo actividades como megaminería, fractura hidráulica y expansión de frontera agrícola, que contribuyen a los efectos del calentamiento global y profundizan conflictos socio ambientales de larga data.

Las propuestas actuales frente al cambio climático no plantean un cambio del sistema productivo, al menos no desde los actores con mayor poder; sí se puede afirmar que hay una mayor conciencia en ese sentido, de parte de los sectores movilizados, que son los que iniciaron 
las manifestaciones masivas en los últimos años. En el mismo sentido, el cambio climático se presenta como un proceso a nivel global, lo cual impide ver otros procesos de deterioro que se han dado a nivel local o regional, donde intervienen también elementos económicos, culturales y políticos. De hecho, el mismo proceso que desencadena el cambio climático, está compuesto de estos elementos, que acaban repercutiendo en el clima. Pero no es algo disociado.

Ese mismo proceso de constitución del sistema capitalista, creó una imagen de naturaleza aislada de la sociedad. La sociedad se enfrentaba a la naturaleza. En cierto modo el término cambio climático da idea de una sociedad enfrentada al medio ambiente. 


\section{BIBLIOGRAFÍA}

Alimonda, H. (comp.) (2011). La naturaleza colonizada. Ecología política y minería en América Latina. Buenos Aires. Ciccus.

Alimonda, H.; Toro Pérez, C. y Martin, F. (Coord.) (2017). Ecología Política Latinoamericana. Buenos Aires. Ciccus.

Bertinat, P. y Ochandio, R. (2018). “¿Qué sucede con las emisiones de metano? ¿La emisión es mayor o menor que la de otras actividades? ¿cómo repercute esto sobre el cambio climático?". En: Bertinat, P. y otros, 20 mitos y realidades del fracking. Buenos Aires. Ed. El Colectivo.

Blaikie, P y Brookfield, H. (1987). Land degradation and society. Londres-Nueva York. Methuen.

Concerned Health Professionals of New York \& Physicians for Social Responsibility, (2015). Compendio de hallazgos científicos, médicos y de los medios de comunicación que demuestran los riesgos y daños del fracking (extracción no convencional de gas y petróleo), 3a edición. Recuperado de: http://concernedhealthny.org/compendium/.

Dussel, E. (2000). “Europa, modernidad y eurocentrismo”. En: La colonialidad del saber: eurocentrismo y ciencias sociales. Perspectivas latinoamericanas. Buenos Aires. CLACSO.

Escobar, A. (2010). Una minga para el postdesarrollo: lugar, medio ambiente y movimientos sociales en las transformaciones globales. Lima. Programa Democracia y Transformación Global. 
Estenssoro Saavedra, F. (2014). Historia del debate ambiental en la política mundial 1945-1992. La perspectiva latinoamericana. Santiago de Chile: Instituto de Estudios Avanzados. Universidad Santiago de Chile.

Fernández, A. (2019). “Palabras del presidente Alberto Fernández en su acto de asunción ante la Asamblea Legislativa". Recuperado de: https://www.casarosada.gob.ar/informacion/ discursos/46596-palabras-del-presidente-alberto-fernandez-en-su-acto-de-asuncion-ante-la-asamblea-legislativa

Fernández, A. (2019). "Palabras del presidente de la nación, Alberto Fernández, durante la Asamblea Anual de la Asociación de Empresas Argentinas (AEA)". Recuperado de: https:// www.casarosada.gob.ar/informacion/discursos/46627-palabras-del-presidente-de-la-nacion-alberto-fernandez-durante-la-asamblea-anual-de-la-asociacion-de-empresas-argentinas-aea

Francisco, (2018). Carta Encíclica Laudato Si' sobre el cuidado de la casa común. Buenos Aires. Ágape Libros.

Galafassi, G. (comp.) (2014). Apuntes de acumulación. Capital, Estado, procesos socio-históricos de (re)producción y conflictividad social. Buenos Aires. Theomai Libros.

Galafassi, G. y Riffo, L. (2017). “Del sueño de Cristóbal Colon al hoy llamado extractivismo. Peripecias y avatares de un largo y continuo proceso de expropiación para la acumulación: 
una necesaria discusión crítica". En: Revista Theomai, №38, pp. 232-244. Recuperado de: https://ri.conicet.gov.ar/handle/11336/73075

Galafassi, G. y Riffo, L. (2018). “Una lectura crítica sobre el concepto de 'extractivismo' en el marco de los procesos de acumulación". En: "Trama. Revista de Ciencias Sociales y Humanidades", Vol.7 (N²), pp. 108-117. Recuperado de: https:// revistas.tec.ac.cr/index.php/trama/article/view/3939/3516

Gudynas, E. (2013). “Extracciones, extractivismos y extrahecciones. Un marco conceptual sobre la apropiación de recursos naturales". En: Observatorio del Desarrollo, №18, pp. 1-18. Recuperado de: http://ambiental.net/wp-content/uploads/2015/12/ GudynasApropiacionExtractivismoExtraheccionesOdeD2013.pdf

Gorz, A. (1979). Ecología y Libertad. Barcelona. Gilli.

Gorz, A. (1980). Ecología y Política. Barcelona. Libros del Viejo Topo.

Harvey, D. (2004). “El 'nuevo' imperialismo. Acumulación por desposesión". En: Social Register, pp. 99-129. Recuperado de: http://biblioteca.clacso.edu.ar/clacso/se/20130702120830/ harvey.pdf 
Keucheyan, R. (2016). La naturaleza es un campo de batalla. Finanzas, crisis ecológica y nuevas guerras verdes. Buenos Aires. Capital Intelectual.

Langhoff, M. L.; Geraldi, A. y Rosell, P. (2017). “El concepto de ciclo hidro social aplicado a los conflictos por el acceso al agua. El caso de la disputa por el río Atuel entre las provincias de La Pampa y Mendoza, Argentina". En: Papeles de Geografía, $N^{\circ}$ 63, pp. 146-160. Recuperado de: https://revistas.um.es/ geografia/article/view/280681

Leff, E. (2006). “La ecología política en América Latina: un campo en construcción". En: Alimonda, H. (comp.) Los tormentos de la materia. Aportes para una ecología política latinoamericana. Buenos Aires. CLACSO.

Lipietz, A. (2002). ¿Qué es la ecología política? Santiago de Chile. LOM Ediciones.

Machado Araoz, H. (2014). Potosí, el origen. Genealogía de la minería contemporánea. Buenos Aires. Mardulce.

Machado Araoz, H. (2010). "Territorio, colonialismo y minería transnacional. Una hermenéutica crítica de las nuevas cartografías del imperio". En: Actas de las III Jornadas del Doctorado en Geografía. Desafíos teóricos y compromiso social en la Argentina de hoy. La Plata, pp. 1-30. 
Martínez Alier, J. (2005). El ecologismo de los pobres. Barcelona. Icaria.

Ochandio, R. (2018). “EEUU: Fracking puertas adentro". En: Bertinat, P. y otros, 20 mitos y realidades del fracking. Buenos Aires. Ed. El Colectivo.

Palacio, G. (2006). "Breve guía de introducción a la ecología política (ecopol)". En: Gestión y Ambiente, Vol 9, N³, pp. 7-20. Recuperado de: https://revistas.unal.edu.co/index.php/gestion/ article/view/49672/57064

Pappalardo, D. (2018). “Argentina: Vaca Muerta como negocio para pocos". En: Centro Andino de Estudios Estratégicos. Recuperado de: https://www.cenae.org/argentina-vaca-muerta-como-negocio-para-pocos.html

Perreault, T. (2015). “Corrientes, colonialismos y contradicciones: repensando las raíces y trayectorias de la ecología política". En: Estudios Atacameños. Arqueología y Antropología Surandinas, $\mathrm{N}^{\circ} 51$, pp. 177-183.

Robbins, P. (2004). Political ecology. Oxford. Blackwell Publishing Ltd. 
Seoane, J. (2011). "Significación y características de las disputas por los bienes comunes naturales en Argentina y América Latina". En: Revista Interdisciplinaria de Estudios Sociales, Vol. 4, pp.7796.

Swyngedouw, E. (2011). "iLa naturaleza no existe! La sostenibilidad como síntoma de una planificación despolitizada". En: Urban, $\mathrm{N}^{\circ} 1$, pp. 41-66. Recuperado de: http://polired.upm.es/index. php/urban/article/view/410

Wehr, I. y Roose, I. (2017). "Contra la corriente: derechos de agua en Chile en el contexto internacional". En: De La Fuente (Dir.) Recuperar el agua. Santiago de Chile. Ed. Aun Creemos en los Sueños.

Wolf, E. (1972). “Ownership and Political Ecology”. En: Anthropological Quaterly, 45, pp. 201-205. 